\title{
The Motivation to Work
}

\author{
Aliya Ahmed and Shadab Fariduddin \\ SZABIST \\ Karachi, Pakistan
}

\begin{abstract}
:
The motivation to work is a research initially done by Frederick Herzberg in 1959 on 200 Pittsburgh engineers and accountants. In this study the research has been replicated on 30 Pakistani professionals associated with marketing and finance departments of four organizations.
\end{abstract}

This research concludes that the factors present in the original study are applicable in the local environment; the strategy also revalidates that factors responsible for motivation are different from factors that cause demotivation.

\section{INTRODUCTION}

In an era of increasing competition, the significance of effectively utilizing all available resources, including human resources, is critical for any company. The motivation of employees is one of the fundamental issues that companies must address in the current marketplace, as it is the key variable that affects employee productivity.

As companies continue to develop organizational initiatives for employee motivation, the application of Herzberg's two-factor theory can contribute to an environment that is conducive to enhanced performance on the part of its most valuable asset: the human resource. This research is about people at work and more precisely it is about their attitude towards their job.

Herzberg's two-factor theory is a very interesting concept and needs to be explored further by applying it to the Pakistani environment. Once applied the findings can be compared to the results of the original study.

\section{OBJECTIVE}

It is very critical for every manager to know about the motivation process and factors responsible for it, the studies of management sciences provide us with the opportunity to work in this field.

The objective of this research is to explore the applicability of Herzberg's theory in Pakistan using the same research method.

\section{PROBLEM STATEMENT}

The main hypothesis of Herzberg theory was that the factors leading to positive attitude and those leading to negative attitudes would differ.
Taking this hypothesis as it is and adding the objective of finding out whether the responses obtained from the sample will be common to the first level, second level and performance effects categories identified by Herzberg, the research was initiated. The first level factors are the description of the objective occurrence during the event with special emphasis on those identified by the respondent as related to his attitude. The second level factors categorize the reason given by the respondents for their feelings and the performance effects give the changes into attitudinal effects beyond the behavioral effects. Specification of mental health effects was also attempted.

In Pakistani corporate culture a varied environment is viewed in Local and Multinational companies. Many of the local companies do not build up on their human resources by neglecting the basic needs of their employees. So through this research we were able to address the issue of finding out what factors play an important role in boosting or lowering employee morale.

\section{METHODOLOGY}

This study uses the same questionnaire and data collection method as in the original study by Fredrick Herzberg. The reason to do this is because it was a tested and validated method. The questionnaires are filled by direct interviews. The interviews are conducted at four organizations, two local and two multinational belonging to different industries like textile, chemical, oil and service. Every effort was made to satisfy the respondents about the confidentiality of the data. A pretest was made in which 5 interviews were conducted to see and check the effectiveness of the questionnaire and the ability of the respondents for understanding the questions. As a result one question was dropped. The interview was conducted in two parts, one focusing the high feelings and the other focusing the low feelings. It was a semi structured interview so a lot of probing is done to get the details about the incidences shared by the respondents which helped in the later part of the research i.e. placing the first, second level factors and performance effects in the responses.

Marketing and Finance professionals of middle management were targeted for the research. Interviews were transcribed before carrying out the analysis. The method of content analysis was used to analyze data. In the original study posteriori approach was used, in this the categories of analysis are extracted from the material itself.

However a priori approach was initially used and tried to fit in the contents already identified in the original study but if 
a suitable category was not identified, a new category was created from the literature and marked with an asterisk.

\section{LIMITATIONS}

There were certain limitations in this research as the original research was conducted with a sample size of 200 people; this research was conducted on a lower scale with a sample size of 30 respondents.

The original research was coded and analyzed in a very comprehensive manner with 3 people working on it. This research is however done addressing two aspects only as explained earlier due to time and resource constraints.

The respondents were asked to keep a span of 5 years time while answering the questions so nothing could be inferred about those particular organizations in which the research was carried out as many respondents shared the experiences from their last jobs.

\section{LITERATURE REVIEW}

On the subject of motivation the work of following leading theorist were taken into consideration before the decision to go for Herzberg's method adoption:

\section{Job satisfaction - is there a trend?}

This is the title of a study carried out by the US Department of Labor among 1500 workers, who were asked to rate the job factors, from a list of 23 , which they considered important starting from the most important factor. It is interesting that out of the 23 job factors listed for the survey, yet with the exception of two items (white-collar workers' choice (b) and blue-collar workers' choice (c)) groups selected the same top ten factors, although with different rankings. It is significant that good pay was considered as the most important factor by the blue-collar workers, but it ranked as the least important for whitecollar workers. [1]

\section{Hierarchy of Need Theory}

The theory given by Maslow in 1954 is a gradual stair like phenomenon which says that one need fulfillment leads to the origination of the next level of need, these needs are defined as Physiological, Safety, Social, Esteem and Self Actualization. The Maslow theory of needs is although very famous but very general as far as its application is concerned. [2]

\section{Theory X Assumptions:}

People inherently dislike work People must be coerced or controlled to do work to achieve objectives

People prefer to be directed

\section{Theory Y Assumptions:}

People view work as being as natural as play and rest People will exercise self-direction and -control towards achieving objectives they are committed to

People learn to accept and seek responsibility

Theory $\mathrm{X}$ and $\mathrm{Y}$ are interesting assumptions however they are not backed by any empirical research. [3]

\section{Three Need theory}

The three need theory advocates three types of needs, Need for achievement like personal responsibility, feedback and moderate risk, Need for power like influence and competitiveness and Need for affiliation like acceptance and friendship and co-operation among individuals The three need theory although covers some of the points mentioned in Herzberg's theory but no solid framework was developed while proposing this theory. [4]

\section{Equity Theory}

- An employee compares her/his job's inputs-outcomes ratio with that of referents.

- If the employee perceives inequity, she/he will act to correct the inequity:

- Voluntary resignation

- Lower productivity

- Reduced quality

- Increased absenteeism [5]

\section{Chris Argyris}

According to Argyris, organization needs to be redesigned for a fuller utilization of the most precious resource, the workers, in particular their psychological energy. The pyramidal structure will be relegated to the background, and decisions will be taken by small groups rather than by a single boss. Work should be restructured in order to enable individuals to develop to the fullest extent. At the same time work will become more meaningful and challenging through self-motivation. Argyris studies motivation for current organizational reality. He emphasizes selfmotivation in view of non-hierarchical structure and joint decision-making however his experiment is ahead of time for Pakistan and consists of complex analysis techniques. [6]

\section{Rensis Likert}

Likert identified four different styles of management:

- exploitative-authoritative;

- benevolent-authoritative;

- consultative;

- participative 
Rensis Likert relates management style to the question of motivation. He found that participative style of management led to a higher degree of motivation. This study could be the second most likely choice but this framework is limited to the decision makers only rather than broad factors/variables contradicting to 'motivation' as in the case with Herzberg. [6]

\section{Fred Luthans}

Luthans advocates the so-called 'contingency approach' on the basis that certain practices work better than others for certain people and certain jobs. As an example, rigid, clearly defined jobs, authoritative leadership and tight controls lead in some cases to high productivity and satisfaction among workers. In some other cases just the opposite seems to work. This theory acts as an advice and no framework is developed for the same. [6]

\section{Victor Vroom}

Vroom's 'expectancy theory' is an extension of the 'contingency approach' but it relates leadership to motivation. The leadership style should be 'tailored' to the particular situation and to the particular group. In some cases it appears best for the boss to decide and in others the group arrives at a consensus. An individual should also be rewarded with what he or she perceives as important rather than what the manager perceives. This work is again a theory without methodology. [6]

\section{Hersey}

Hersey studied the variation of feelings about the job within the individual at different times. In one of his best known studies he examined the cyclical nature of feelings about the job was related to the frequency of accidents. Workers kept a diary of their moods and records of accidents, the finding was that a large proportion of these accidents occurred during periods in which the people identified their moods as low. This research was limited to factory settings only. [6]

\section{Fredrick Herzberg}

The Motivation to Work, the book written by Mr. Fredrick Herzberg, Bernard Mainer and Barbara Snyderman in 1959 has become one of the most replicated studies in the field of workplace psychology. Herzberg showed that certain factors truly motivate ('motivators'), whereas other tended to lead to dissatisfaction ('hygiene factors'). Herzberg was found to be most appropriate both from theoretical soundness and methodological ease.

For conducting this research the original book of Fredrick Herzberg was read in detail to understand the objective, methodology and results of the original study. It was an experience of joy as the research is conducted and presented in such a beautiful manner that it grasps the readers' attention till the very end. Besides the original research some other foreign literature is also reviewed however I was not able to find any extensive work done on the subject in Pakistan. This lack created difficulty in identifying possible problematic issues for the study beforehand. However I took it as an opportunity for making original contribution to knowledge based on local settings. [7]

\section{RESULTS/FINDINGS}

It is seen that in the high feelings four factors accounts for nearly $70 \%$ which are those factors which people expect from their jobs like advancement, recognition, growth and achievement whereas the factor leading to low attitude are several but not about the job as such but about the conditions. Another interesting fact to note here is in Herzberg original study Misbehavior by Supervisor is missing in the categories, which is reported by $13.33 \%$ of the respondents in our environment. Other two factors, which show high percentages, are unfriendly relations with supervisor and harmful personnel policies thus indicating that major chunk of people have experienced low morale due to poor conditions.

$57 \%$ of the respondents in high feelings agreed that the incident they have mentioned has affected their career positively against a minor $16.66 \%$ of the respondents of low feelings who told that that the incident has affected their career negatively. Thus it can be interpreted that the factors reported in high feelings are the factors that can contribute mainly in the career development whereas factors mentioned in low feelings actually do not contribute in career development. And in the negative feelings it is interesting to note that respondents even mentioned about a better career after the incident. $13.33 \%$ of the respondents told that the incident has affected their career positively as they have left the job and doing a better job now.

Table 1

\begin{tabular}{|l|c|}
\hline $\begin{array}{l}\text { High Feeling respondents reporting incident } \\
\text { has affected the career positively }\end{array}$ & $57.00 \%$ \\
\hline $\begin{array}{l}\text { Low Feeling respondents reporting incident } \\
\text { has affected the career negatively }\end{array}$ & $16.66 \%$ \\
\hline $\begin{array}{l}\text { Low Feeling respondents reported a better } \\
\text { career after the incident }\end{array}$ & $13.33 \%$ \\
\hline
\end{tabular}

In the response to a question asked regarding the meaning of events to the respondents, $80 \%$ of the respondents were able to correlate the first level factors to a feeling of growth, achievement, pride, work enrichment etc. where as in negative feelings the factors identified are varied but an interesting fact to note here again is unlike the original study many respondents identified First level factors leading to the feelings of frustration which is incorporated in the findings.

In high feelings $50 \%$ of the respondents did believe that their feelings for the profession are changed after the incident whereas in low feelings only $10 \%$ of the respondents said that the feelings for profession have 
changed after the incident so it could be inferred that positive feelings leads to a change of feelings towards profession whereas negative feelings do not mainly affect the feelings towards the profession.

Table 2

\begin{tabular}{|l|c|}
\hline $\begin{array}{l}\text { High Feelings respondents believe that there } \\
\text { feelings changed for the profession after the } \\
\text { incident }\end{array}$ & $50 \%$ \\
\hline $\begin{array}{l}\text { Low Feelings respondents believe that there } \\
\text { feelings changed for the profession after the } \\
\text { incident }\end{array}$ & $10 \%$ \\
\hline
\end{tabular}

$50 \%$ of the respondents gave specific reports of positive changes in quality or output of work whereas only $40 \%$ of the respondents were able to give specific reports of negative changes in quality and output of work.

Table 3

\begin{tabular}{|l|c|}
\hline $\begin{array}{l}\text { Respondents gave specific reports of positive } \\
\text { changes in quality and output of work }\end{array}$ & $50 \%$ \\
\hline $\begin{array}{l}\text { Respondents gave specific reports of negative } \\
\text { changes in quality and output of work }\end{array}$ & $40 \%$ \\
\hline
\end{tabular}

$83 \%$ of the respondents gave the intensity of feelings from average to high in high attitude whereas $64 \%$ gave the intensity of feelings from average to high in low attitude but a significant percentage is seen on a very high scale in low feelings thus proving that in negative circumstances the intensity of the feelings are very high as compared to positive feelings.

Table 4

\begin{tabular}{|l|c|}
\hline $\begin{array}{l}\text { High feelings respondents gave intensity of } \\
\text { feelings from average to high. }\end{array}$ & $83 \%$ \\
\hline $\begin{array}{l}\text { Low feelings respondents gave intensity of } \\
\text { feelings from average to high. }\end{array}$ & $64 \%$ \\
\hline
\end{tabular}

\section{CONCLUSION}

The research findings tend to prove the hypothesis that the factors leading to positive attitude and those leading to negative attitudes are different. It could also be said that the categories mentioned by the content analysis technique are mostly applicable in our environment. The major drift is seen in low feelings where some categories were added to record the responses. Only one part of the original research has been replicated for the study; this research could be applied for various objectives in different working conditions. The extension of this study is also possible where the responses could be coded as the sequences mentioned in the original research.

The study makes an original contribution to the study of motivation among Pakistani Professionals. It is hoped that it will lead to similar works in future, particularly with respect to research areas identified herein

\section{REFERENCES}

[1] www.accel-team.com/motivation/index.html Date accessed : September 25, 2004.

[2] Abraham Maslow, Motivation and Personality, 1954, HarperCollins Publishers; 3rd edition (January 1, 1987)

[3] Douglas McGregor, The Human Side of Enterprise, 1960, McGraw-Hill/Irwin; 1 edition (August 1, 1985)

[4] David McClelland, The Achieving Society, 1961, Free Press; Reissue edition (February 1, 1967)

[5] J. Stacey Adams, 1965.

[6] www.accel-team.com/motivation/index.html Date accessed : September 25, 2004.

[7] Frederick Herzberg, The Motivation to Work, 1959, Transaction Publishers; Reprint edition (January 1, 1993) 